\title{
Study on the Building of Ecological Design Concept in the Teaching of Environmental Design in Colleges and Universities
}

\author{
Zhang Zhengwei \\ Academy of Fine Arts, Shandong Normal University, Jinan 250000, China \\ zhangzhengwei@126.com
}

Keywords: Environmental design, Ecological design, Anti planning concept

\begin{abstract}
The construction of ecological civilization has become the theme of today's social development. All kinds of project design and construction are integrated into the concept of ecological design. The building of ecological design concept in university environmental design teaching is particularly important. Breaking disciplinary boundaries, environmental design, teaching extension, ecological content, case analysis teaching, classroom teaching combined with practice teaching and anti-planning concept, environmental design teaching are effective ways to establish students' ecological design concept.
\end{abstract}

\section{The concept of ecological design}

Any design form that is coordinated with the ecological process to minimize the damage to the environment is called the ecological design [1]. Ecological design, also known as environmental design, refers to the inclusion of environmental factors in the design and the determination of the direction of the design. Ecological design requires environmental factors to be considered in all stages of product development. The whole life cycle of products should be reduced to environmental impact, resulting in sustainable production and consumption system. Environmental design involves many disciplines, extensive influence, according to the size of the affected areas of ecological design can be divided into macro and micro ecological design, ecological design, micro ecological design can refer to environmental design, both from a macro or micro perspective ultimately refers to the minimum environmental cost to design cost-effective products or a comfortable and healthy living space. The object of ecological design can be the industrial layout design of the whole country. It can be urban planning and design, landscape design, architectural design and interior design, and also the packaging design of goods, and the design of single product. No matter which refers to a design, but involves the scope size, purpose is one that is less damage to the environment or environmental restoration, embodies the artistic creation, keep and show a certain geographical humanities and social landscape, and ultimately promote the harmonious and sustainable development of human health, protect the environment capable of carrying human long.

\subsection{Macro ecological design}

Macro ecological design refers to the broad category of ecological design. It refers to planning people's production and life. We must consider the environmental carrying capacity and the comprehensive impact on the environment, including the impact on culture, art and geography. The impact of macro ecological design on the environment is extensive and long-term, and it is most easily ignored by people. People should constantly transform the world and get a good living environment through transforming the world. If this process cannot be designed and grasps properly, it will become a predation on environment and eventually will aggravate the living environment of mankind. If the unreasonable industrial layout, unreasonable urban planning, unreasonable consumption concept will deteriorate the people's living environment. Examples are given to illustrate some aspects of the macro ecological design.

The Loess Plateau in the past was once one of the regions with good natural conditions. Because of 
the excessive logging and agricultural development, the rulers of the past dynasties failed to do the ecological design of the region, resulting in today's outcome. The overgrazing caused the grassland degradation and the desert invasion. These are all history, and people have begun to control the bitter fruit after they have tasted the bitter fruit. At this stage the air haze, water pollution, toxic land, food pollution, noise pollution, traffic congestion in the city, hawkers and urban management disputes belong to the macro ecological design category. Macro ecological design is the design and guidance of system, planning, standard and people's living habits. It is a kind of high level ecological design.

\subsection{Environmental protection ecological design}

A design project or individual follow the requirements to design the national environmental protection and sustainable development strategy, fully embodies the concept of environmental protection, to find the common denominator between performance, comfort and reduce environmental damage. It refers to the aspects of project planning, technology, materials, life, degradation and reuse, which should meet the requirements of environmental protection and reduce resource consumption and environmental impact. The design of high energy consumption, heavy pollution, excessive packaging, lack of waste recycling and treatment, and no attention to human's emotional and physical health are all contrary to the environmental and ecological design.

\section{Cultivation of the concept of ecological design in the teaching of environmental design in colleges and universities}

Environmental design in Colleges and universities is a rapid development of the main design categories, including architectural design, landscape design, interior design, public art design, reflects the environmental and artistic features, but the content is relatively narrow, we on students' ecological design concept cultivation should be beyond the range, to the use of natural ecology and cultivation the theory of management to influence students' ecological philosophy, natural ecology and management can be effectively combined to form the ecological design idea. This can be thought of ecological design macro ecological design and eco design, eco design of heavy macro management, environmental and ecological design and implementation, because of the increasing trend of social development we pay more attention to environmental protection, employment and students may engage in different levels of work, so we ecological design concept of the cultivation of students "should be in a certain degree beyond the environmental design professional needs. The teaching of environmental design should be the professional redesign, the design of the ecology, and the selfenvironmental control and management ability of the design work.

\subsection{Environmental design teaching extension of human ecology and natural ecological protection content}

The focus of the environment design teaching students is the design, which embodies the ecological protection characteristics of the ecological design. General requirements for environmental protection will be proposed in the teaching process, namely low carbon, energy saving, environmental protection and humanized design, and reflected in design, often students in environmental design passively, used to comply with the design requirements and design specifications of ecological design, lack of awareness and take the initiative to avoid environmental problems the concept of ecological design, easy to walk in the edge of the standard and requirement, the lack of enterprising consciousness and responsibility consciousness of ecological environment, ecological design is not conducive to the perfection and upgrading. How to change passive compliance into active perfection and optimization requires that we should improve students' awareness of ecological knowledge and ecological crisis in environmental design teaching, so as to cultivate students' ecological design concept and consciousness.

The front said environmental design is focused on the design of teaching knowledge, to reflect the ecological protection in the process of teaching is often the design requirements and specifications, the students will not have a strong awareness of environmental protection, so we should design the 
teaching environment in Chinese and foreign extension of human ecology and natural ecology knowledge, like the outlook on life education as erected students' awareness of environmental protection concepts and ecological protection. Only by enhancing the knowledge of human ecology and natural ecology, can we fully understand the importance of ecological design, so that we can command actions from consciousness and maximize the characteristics of ecological protection in design.

Modern college students accept knowledge education comprehensively, jobs will be engaged in different jobs, as employees may be engaged in the design of concrete directly, as the management may be involved and design units on environmental ecological development strategy, to engage in a higher level of work will face or participate in making macro ecological design environment the design standard, all need to have some basic knowledge and knowledge of ecology environment design and ecological design strong consciousness.

To cultivate the macro ecological design concept should be integrated in design process of teaching environment, teaching in the design process of continuous penetration of human ecology and natural ecology protection knowledge, to enable every student to understand ecological protection, ecological protection of desire, as a doctor of bacteria and viruses so profound understanding. Through the design of macro ecological concept accepted by students, students in the eco design process deliberately focusing on environmental and ecological problems, not only to meet the requirements of environmental protection design, the design is not responsible for the requirements of ecological problems abroad. Therefore, environmental design teaching should extend and expand the teaching of human ecology and natural ecological protection, and improve environmental design teaching to a higher level of discipline education.

\subsection{Case Analysis Teaching}

Anything want to deepen the understanding must be combined with case analysis, through the case of enumeration can deepen understanding of things, especially on the wrong understanding to the concept of ecological design and cultivation of students. In real life, there is no lack of failures in designing or breaking the rules of ecology. Painful lessons can deepen students' sense of crisis and responsibility, and help students develop their ecological design ideas. Some violations of the natural and human ecological rules case projects are being implemented, but the majority of people do not realize, as environmental design teachers must dare to correct, only teachers have a sense of play, students can adhere to the concept of ecological design, not all kinds of interference factors.

Case analysis of materials can be collected from these aspects: the failure of foreign and domestic water conservancy project; major mistakes Chinese city planning history (such as the destruction of old Beijing and planning); city traffic congestion, waterlogging problem, problem of conflict city street pedlars and chased the ghost; problems; problems of city light pollution noise pollution; indoor decoration pollution; the destruction of the ozone layer fluorine refrigerant; the waste disposal problem of excessive packaging; management about ecological design problems (such as to go waste contributions to several issues); nuclear accident pollution problem in the world. Analysis of various case teachers should not avoid emotional, should actively pointed out the key problem, to solve the problem at this stage not should be clearly pointed out that the reason and way of environmental events of public opinion should be taken seriously, adhere to the principle of position, analysis of problems with the scientific method, we can not do the eyes of the masses "brick house" give up the science and education workers personality to Afu dignitary, do teachers the concept of ecological firm, set a good example for the students.

\section{The combination of classroom teaching and practical teaching}

For the design of teaching environment, breaking the disciplinary boundaries, extending knowledge and case teaching can be a certain degree of enumeration to strengthen the cultivation of ecological design idea, but that is not enough, also need to be further through the form of practice teaching to strengthen the cultivation of ecological design, can carry out social ecological 
investigation practice and virtual design practice to strengthen the understanding the theory of knowledge and the concept of ecological design and firm, to cultivate students' concept of ecological design. Knowledge comes from practice, belief comes from cognition, and the curing of cognition comes from direct contact with things. We can through direct contact of things to understand things, to get things identity, ecological design idea and stick to curing must have a direct personal experience to deepen the understanding and feelings, therefore teaching environment design concept of ecological design approval and stick to the practice of students cannot do without investigation, through practice and investigation, students can to further strengthen the concept of ecological design.

With the development of modern science and technology, there are two forms of practice. A practice is usually meaning, namely the people directly involved in things that participate in the practice and investigation of reality, the other is a virtual practice, is a kind of through the virtual cyberspace activities by virtual technology support of virtual practice opened up a hitherto unknown world of human practice in the new space between the human activities of the expanded to a new unknown [2]. Virtual practice is a practical activity combined with modern information technology, which has the advantages that the practice does not have.

The practice of social ecological investigation can be carried out from the scope of students' living environment. First of all, students live in natural and human ecological environment. They have personal experience and feelings. In fact, students have begun to practice in this aspect in their life process, but students do not pay much attention to it. The social ecological investigation practice task of teachers in the arrangement of students only need to put forward specific requirements for students through practice, students are required to complete certain subjects, to encourage students to watch and thinking of environmental and ecological issues and events around, to enhance the awareness of environmental protection through the ecological and environmental problems concerned with the cultivation of the firm, the concept of ecological design.

The virtual practice of ecological design has unparalleled advantages for the teaching of environmental design to cultivate the concept of ecological design for students. First of all, the virtual eco design without consuming any resources, no time, no cost, allowed to make mistakes and mistakes, just like a wargame virtual war, no price can gain experience and experience. When carrying out the practice of virtual ecological design, students should be allowed to make mistakes or mistakes. We should enhance our understanding through virtual practice activities, especially the misunderstanding of ecological design and erroneous cognition, so as to strengthen students' ecological design concept through understanding. If we can carry out such a virtual practice of ecological design: through the formulation of rules conforming to the laws of humanity and natural ecology, let students design and construct a water conservancy facility in a river and run it for twenty years to get ecological experience data, so as to enhance the concept of ecological design. For example, we can let students plan a small and medium-sized virtual city and develop the city for ten years, so as to cultivate students' ecological design concept through the emergence of environmental and ecological problems.

\section{Anti planning concept and ecological design}

In the teaching of environmental art design, the idea of anti planning is widely used. Especially in the construction of ecological civilization city, the role of anti planning concept is very important [3]. By observing the latest developments in current affairs, we can find that in recent years, the state and society increasingly pay attention to the harmony between man and nature. The concept of ecological civilization has been introduced into urban and rural construction. The concept of anti planning, like its name, is a more casual plan, which reduces man-made environmental planning, and makes use of the adjustable and self healing of ecological environment to plan. It keeps the vitality of the whole urban ecosystem and promotes the harmonious development of human and nature. The formation of the concept of anti planning is a scientific truth gradually realized in the process of human transformation of the world, that is, nature's bestowing to mankind is probably our best choice. The 
pursuit of harmony between human and nature is the trend of the future ecological design, which is being accepted by more and more people. Therefore, the concept of anti planning should be emphasized in the teaching of environmental design, and the concept of ecological design should be cultivated by strengthening the concept of anti planning.

\section{References}

[1] Sim van der Ryn and Cowan, Stuart. Ecological Design[M]. Wasllingt0n D\&amp; Island Press, 1996.

[2] Zhang Guoyan. The theory of [J]. in virtual practice, 2009 (32): 65-66.

[3] Ding Yi. The application of the idea of anti planning in the teaching system of environmental art [J]. modern vocational education, 2017,13:26. 